\title{
Duration of the pubertal growth spurt in patients with increased craniofacial growth component in sagittal and vertical planes-retrospective and cross-sectional study
}

\author{
Agnieszka Szemraj-Folmer $^{1}$ [D - Anna Wojtaszek-Słomińska ${ }^{1} \cdot$ Bogna Racka-Pilszak $^{1}$ • Małgorzata Kuc-Michalska ${ }^{2}$
}

Received: 17 August 2020 / Accepted: 14 January 2021 / Published online: 5 February 2021

(C) The Author(s) 2021

\begin{abstract}
Objectives The aim of the study is to assess the skeletal age at the onset and end of the pubertal growth spurt and determine its duration in four growth type groups: (1) normodivergent skeletal Class I (I N), (2) normodivergent skeletal Class III (III N), (3) high-angle skeletal Class III (III H) and (4) high-angle skeletal Class I (I H).

Materials and methods Two hundred thirteen subjects were selected from 2163 examined files. The cervical vertebral maturation stage was recorded by means of Baccetti's method. The sagittal and vertical skeletal relations were evaluated according to Steiner analysis with Kaminek's modification. The duration of the pubertal growth spurt was calculated from the difference between the means of the chronological age related to CS3 and CS4 maturation stages.

Results The shortest lasting pubertal growth spurt was observed in group I N (1.1), followed by group III N (1.6). Major differences between arithmetic means CS4-CS3 were seen in groups I H and III H (2.3 and 2.7, respectively).

Conclusions The following tendency was observed in the duration of the pubertal growth spurt: I N $<$ III $N<$ I H $<$ III H. This tendency has statistical significance only in high-angle patients in comparison with normodivergent skeletal Class I.

Clinical relevance Knowledge on the longer pubertal growth spurt in high-angle patients compared to patients with normal anteroposterior and vertical relationships can be useful in the selection of an appropriate therapeutic method and a treatment time.
\end{abstract}

Keywords Growth spurt · Growth spurt duration · Cervical vertebral maturation · Cephalometric measurements

\section{Introduction}

In humans, pubertal growth spurt is a period of many, often intense, changes in the body. Observation of a juvenile patient in this period can significantly impact the choice of a suitable

Agnieszka Szemraj-Folmer

agnieszkaszemraj@gumed.edu.pl

Anna Wojtaszek-Słomińska

aslom@gumed.edu.pl

Bogna Racka-Pilszak

bracka@gumed.edu.pl

Małgorzata Kuc-Michalska

ortomikar@interia.pl

1 Department of Orthodontics, Faculty of Medicine, Medical University of Gdańsk, Al.Zwyciestwa 42c, 80-210 Gdańsk, Poland

2 Private Orthodontic and Dental Clinic, ul.Pawliczka 10/1, 41-800 Zabrze, Poland orthodontic-orthopaedic therapeutic method. If treatment is deferred at the time, the growth potential may be irreversibly lost [1]. For this reason, assessment of the skeletal age when patients with orthodontic problems are diagnosed is so important $[2,3]$.

A number of methods can be used to determine the skeletal age. To evaluate the patient's maturation stage, one can examine a radiograph of the hand and the wrist [4], the knee [5] or a cephalometric x-ray picture. Methods heretofore used to analyse the morphology of the vertebrae have been modified many times and improved $[6,7]$. The most recent modification of the cervical vertebral maturation (CVM) stages is the one proposed in 2005 by Baccetti, Franchi and McNamara (Fig. 1) [8]. It is this classification which has gained many supporters and opponents. The main objection is that CVM method is characterised by lack of repeatability and lack of specific features that can be used to define each stage $[9,10]$. There are studies, however, that confirm both repeatability and correlation between CVM and HWM [11-13]. The CVM method does not require additional radiographic documentation since the vertebrae are examined on a cephalometric radiograph — a standard for 
Fig. 1 Cervical vertebral maturation method according to Baccetti, Franchi and McNamara (2005). Source: Baccetti T, Franchi L, McNamara JA Jr. (2005) The cervical vertebral maturation (CVM) method for the assessment of optimal treatment timing in dentofacial orthopedics. Seminars in orthodontics 11:119 129

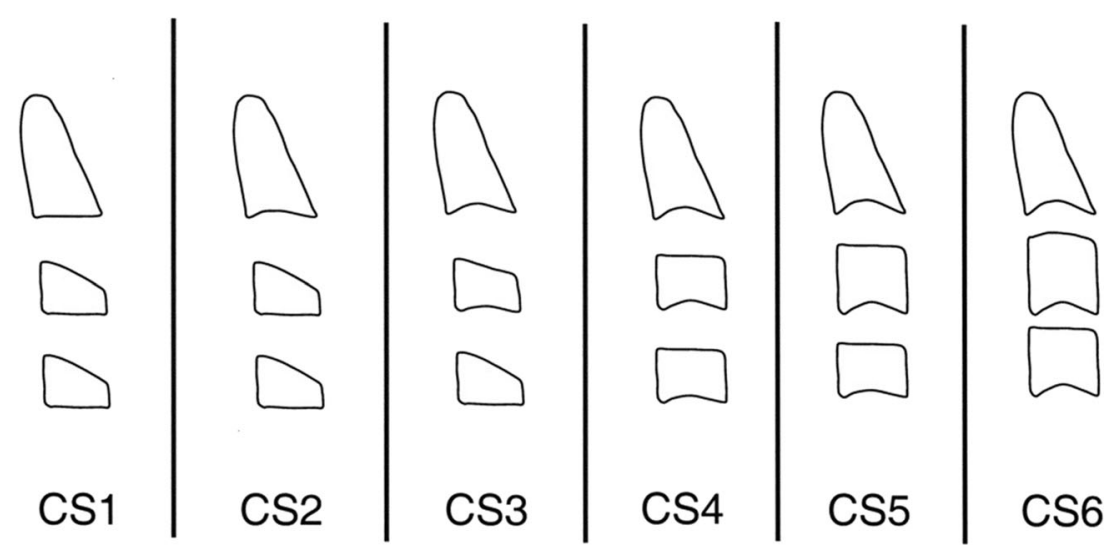

diagnosing malocclusions $[8,14]$. The hand-wrist method, accepted as the "gold standard", involves taking a radiograph, whose sole purpose is to determine the bone age. It has to be stressed that during the therapeutic process of the growing patient, a determination of the skeletal age - which often does not correlate with the chronological age [15-17] — needs to be performed several times. The benefit of the CVM method is the elimination of unnecessary exposure of the patient to radiation - a vital element in today's radiological protection. According to the authors, the most intense mandibular growth, which occurs during the pubertal growth spurt, occurs between the CS3 and CS4 stage [8].

The pubertal growth spurt is characterized by dynamic mandibular growth and less noticeable maxillary growth [8, 18]. Significant gender differences can be observed in this period; therefore, all possible deviations have to be considered individually [1]. Females mature faster, by about 2 years, than males [19]. Generally speaking, maturation stages in boys are more difficult to pinpoint than in girls because they are less specific [20]. Other factors also significantly impact the maturation process, namely hormonal changes, the environment, genetics, climate and nutrition [21]. Studies indicate that the pubertal growth spurt is also different in populations with various types of skeletal malocclusion. The most frequently observed correlation can be defined as follows: the pubertal growth spurt is shorter in skeletal Class II and takes longer in Class III in comparison with patients with normal anteroposterior and vertical cephalometric measurements [22-24]. However, studies on pubertal growth spurt in patients with vertical plane disorders are still scarce [25]. Due to vertical craniofacial growth, which lasts longer than the transverse or the sagittal ones, it was important to check whether the increased vertical growth component is reflected in the duration of the pubertal growth spurt [26].

The aim of the study is to assess the skeletal age at the onset and end of the pubertal growth spurt and determine its duration in four groups: normodivergent skeletal Class I; normodivergent skeletal Class III; high-angle, skeletal Class III (with skeletal open bite); and high-angle skeletal Class I (with skeletal open bite).

\section{Material and methods}

This is a retrospective, cross-sectional study.

Ethical approval was obtained from The Independent Bioethics Committee at The Medical University in Gdańsk prior to data collection (NKBBN/43/2017). This study was performed in line with the principles of the Declaration of Helsinki.

The sample size was calculated by the G*Power software, version 3.1.9.7. Basing on the pilot study, the following assumptions were made: a two-tailed test with a power of $90 \%$, a significance level of $p=0.05$, the effect size $\mathrm{d}$ of 1 and an allocation ratio of 1 . The minimal sample size was 23 individuals in one group. A total of 213 patients qualified for the study; the least numerous group comprised 25 individuals.

A database of cephalometric radiographs (2163 in total) was reviewed in order to collect the study material. The radiographs were taken of patients who presented at the Department of Orthodontics, Medical University of Gdańsk and Private Orthodontic and Dental Clinic in Zabrze, Poland between 2008 and 2019. When making the selection, the most important common criterion was CS3 stage (which correlated with the onset of the pubertal growth spurt) or CS4 (indicating the end of the pubertal growth spurt) acc. to the CVM six maturation stages proposed by Baccetti et al. [8]. Patients with concavity at the base of $\mathrm{C} 2$ and $\mathrm{C} 3$ were qualified for stage CS3, provided the concavity at $\mathrm{C} 4$ was absent. $\mathrm{C} 3$ and $\mathrm{C} 4$ were trapezoid in shape or resembled a horizontally positioned rectangle. For the CS4 stage, patients manifesting $\mathrm{C} 2, \mathrm{C} 3$ and $\mathrm{C} 4$ concavity were qualified. C3 and C4 vertebrae had the shape of a horizontally positioned rectangle. Other inclusion criteria included age (7-18 years) and good quality radiographs. Patients who had previously undergone orthodontic treatment, had clefts or genetic disorders were excluded from the study. Skeletal criteria acc. to Steiner's analysis with Kaminek's modification defining individual groups were: normodivergent skeletal Class I-WITS $=0 \pm$ $2 \mathrm{~mm}, \mathrm{NS} / \mathrm{ML}=33 \pm 6^{\circ}$ (I N); normodivergent skeletal 
Class III-WITS $<-2 \mathrm{~mm}, \mathrm{NS} / \mathrm{ML}=33 \pm 6^{\circ}$ (III N); highangle skeletal Class III-WITS $<-2$, NS $/ \mathrm{ML}>39^{\circ}$ (III $\mathrm{H}$ ); high-angle Class I-WITS $=0 \pm 2 \mathrm{~mm}, \mathrm{NS} / \mathrm{ML}>39^{\circ}$ (I H).

The first selection of radiographs produced 768 pictures. Of this total, a number of radiographs were excluded due to 151 - other skeletal discrepancies (i.e. Class II or deep bite), 189-inadequate CVM stage, 123-incomplete orthodontic records, 92-genetic disorders or clefts. Eventually, 213 radiographs were obtained, which were allocated to eight groups including the following number of patients: I N, CS3-29 patients; I N, CS4-29; III N, CS3-25; III N, CS4-25; III H, CS3-28; III H, CS 4-25; I H, CS3-25; I H, CS4-27. No single patient was categorized as both CS3 and CS4 stages.

The following parameters were adopted when cephalometric radiographs were being taken with Gendex Ortoralix 9200: 68-72 kV, $8 \mathrm{~mA}$ and $1 \mathrm{~s}$. In order to eliminate any measurement error, the CVM stages and cephalometric measurements were assessed by two independent researchers at 1-month interval. The two obtained parameters served to calculate the arithmetic mean. Assessment of three cervical vertebrae was made with Baccetti's method, which takes into consideration the depth of $\mathrm{C} 2 \mathrm{~m}, \mathrm{C} 3 \mathrm{~m}$ and $\mathrm{C} 4 \mathrm{~m}$ concavity (the concavity had to represent at least $10 \%$ of the posterior height of the vertebral structure), as well as the value of C3BAR, C3PAR, C4BAR and C4PAR parameters (Fig. 2) [8]. The intra- and interobserver agreement was expressed by kappa coefficient. The values of kappa gave a result of 0.92 (inter-) and 0.94 (intra-) observer agreement.

In cases when there were discrepancies in classification of CVM stages, the researchers reached agreement by means of exchange of opinions and discussion.

\section{Statistical analysis}

All statistical calculations were made by means of the R software, version 3.6.3. (2020) and Excel 2010 spreadsheet. Quantitative variables were characterized by means of the arithmetic mean and standard deviation. To check whether the examined variable for each group comes from a normal distribution, the Shapiro-Francia test for normality (with Benjamini-Hochberg's modification) was used. Group homogeneity was confirmed with Levene's analysis. The significance of the differences between stage CS3 and CS4 for each type of malocclusion was calculated using the Student's $t$ test for independent samples. Arithmetic mean in different groups for stages CS3 and CS4 were compared using the ANOVA and post-hoc Tukey tests. The duration of the pubertal growth spurt was calculated from the difference between the means of the chronological age related to CS3 and CS4. Next, the duration of the pubertal growth spurt was compared between groups by means of a linear model with interaction effects. For all the tests, the significance level was set at $p<0.05$.
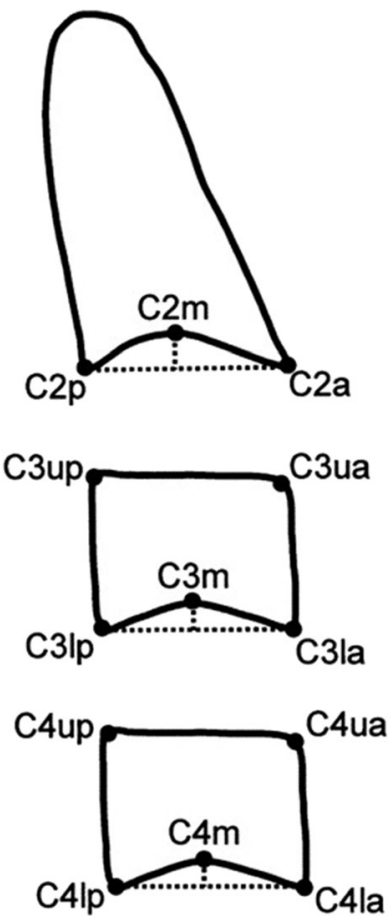

Fig. 2 Vertebral points, measures and ratios used to determine the vertebral stage in the CVM method. C3BAR: ratio between the length of the base (distance C3lp-C3la) and the anterior height (distance C3uaC3la) of the body of C3. C3PAR: ratio between the posterior (distance C3up-C3lp) and anterior (distance C3ua-C3la) heights of the body of C3. C4BAR: ratio between the length of the base (distance C4lp-C4la) and the anterior height (distance C4ua-C4la) of the body of C4. C4PAR: ratio between the posterior (distance C4up-C4lp) and anterior (distance C4uaC4la) heights of the body of C4. Source: Baccetti T, Franchi L, McNamara JA Jr. (2005) The cervical vertebral maturation (CVM) method for the assessment of optimal treatment timing in dentofacial orthopedics. Seminars in orthodontics 11:119-129

\section{Results}

A total of 213 cephalometric radiographs were accepted for the study including 129 female and 84 male patients. The evaluation of the bone age at the onset and end of pubertal growth spurt has been presented here using descriptive statistics (Table 1). The lowest mean for the CS3 stage was recorded for groups III H and I N (10.72. and 10.74, respectively), and for the CS4 stage also in group I N (11.81). For patients in group III N, the growth spurt started the last (11.94), and ended the last in I H (13.76). The maximum age in stage CS4 was the highest in high-angle patients (I H and III H17.42). Separate calculations for both genders have also been included in tables; they are supposed to add a perspective since the requirement of the minimal number of patients in a given group was not met. The most significant gender differences were observed in group III $\mathrm{H}$ - the onset of pubertal growth spurt occurred even 2 years later in males than in females, and ended 1 year later at the most.

In all the groups, arithmetic mean for stage CS3 significantly differed statistically from those for stage CS4 (Table 2). 
Table 1 Descriptive statistics

\begin{tabular}{|c|c|c|c|c|c|c|c|}
\hline Gender & $\begin{array}{l}\text { Type of } \\
\text { malocclusion }\end{array}$ & $\begin{array}{l}\text { CVM } \\
\text { stage }\end{array}$ & $\begin{array}{l}\text { No. of } \\
\text { records }\end{array}$ & $\begin{array}{l}\text { Mean age } \\
\text { [year] }\end{array}$ & $\begin{array}{l}\text { Standard } \\
\text { deviation }\end{array}$ & $\begin{array}{l}\text { Minimum } \\
\text { age [year] }\end{array}$ & $\begin{array}{l}\text { Maximum } \\
\text { age [year] }\end{array}$ \\
\hline \multirow{8}{*}{$\begin{array}{c}\text { Female } \\
+ \\
\text { Male }\end{array}$} & \multirow[t]{2}{*}{ I N } & CS3 & 29 & 10.74 & 0.94 & 9 & 12 \\
\hline & & CS4 & 29 & 11.81 & 1.41 & 9.33 & 14.92 \\
\hline & \multirow[t]{2}{*}{ III N } & $\mathrm{CS} 3$ & 25 & 11.94 & 1.47 & 9.92 & 14.75 \\
\hline & & CS4 & 25 & 13.5 & 1.42 & 11 & 16.33 \\
\hline & \multirow[t]{2}{*}{ III H } & $\mathrm{CS} 3$ & 28 & 10.72 & 1.7 & 7.42 & 13.58 \\
\hline & & CS4 & 25 & 13.4 & 1.81 & 10.08 & 17.42 \\
\hline & \multirow[t]{2}{*}{ I H } & $\mathrm{CS} 3$ & 25 & 11.49 & 1.51 & 8.75 & 14.5 \\
\hline & & CS4 & 27 & 13.76 & 1.86 & 9.5 & 17.42 \\
\hline \multirow[t]{8}{*}{ Female } & \multirow[t]{2}{*}{ I N } & CS3 & 19 & 10.57 & 1.01 & 9 & 11.75 \\
\hline & & CS4 & 17 & 11.5 & 1.24 & 9.33 & 14.5 \\
\hline & \multirow[t]{2}{*}{ III N } & $\mathrm{CS} 3$ & 13 & 11.17 & 1.51 & 9.92 & 14 \\
\hline & & CS4 & 13 & 13.19 & 1.16 & 11.92 & 14.92 \\
\hline & \multirow[t]{2}{*}{ III H } & $\mathrm{CS} 3$ & 20 & 10.16 & 1.56 & 7.42 & 12.67 \\
\hline & & CS4 & 14 & 12.95 & 0.93 & 11.5 & 14.5 \\
\hline & \multirow[t]{2}{*}{ I H } & $\mathrm{CS} 3$ & 14 & 11.14 & 1.4 & 8.75 & 13.67 \\
\hline & & CS4 & 19 & 13.82 & 1.85 & 9.5 & 17.25 \\
\hline \multirow[t]{8}{*}{ Male } & \multirow[t]{2}{*}{ I N } & $\mathrm{CS} 3$ & 10 & 11.07 & 0.71 & 10.08 & 12 \\
\hline & & CS4 & 12 & 12.26 & 1.57 & 10.75 & 14.92 \\
\hline & \multirow[t]{2}{*}{ III N } & CS3 & 12 & 12.54 & 1.2 & 11.25 & 14.75 \\
\hline & & CS4 & 12 & 13.85 & 1.64 & 11 & 16.33 \\
\hline & \multirow[t]{2}{*}{ III H } & $\mathrm{CS} 3$ & 8 & 12.11 & 1.19 & 9.92 & 13.58 \\
\hline & & CS4 & 11 & 13.96 & 2.48 & 10.08 & 17.42 \\
\hline & \multirow[t]{2}{*}{ I H } & $\mathrm{CS} 3$ & 11 & 11.95 & 1.58 & 9.42 & 14.5 \\
\hline & & CS4 & 8 & 13.63 & 2.03 & 11.75 & 17.42 \\
\hline
\end{tabular}

In order to compare stage CS3 and CS4 between all the groups, the ANOVA analysis of variance was performed. Whenever the result was statistically significant, the posthoc (Tukey HSD test for normal distribution) was used to check the differences between particular groups (Table 3). The mean chronological age for stage CS3 did not show significant statistical differences between groups defined

Table 2 The comparison of mean ages between CS3 and CS4 stages in groups with different types of malocclusion

\begin{tabular}{llllll}
\hline & & I N & III N & III H & I H \\
\hline Male + Female & CS3 & 10.74 & 11.94 & 10.72 & 11.49 \\
& CS4 & 11.81 & 13.5 & 13.4 & 13.76 \\
\multirow{3}{*}{ Female } & $p$ value & $0.001 *$ & $<0.001^{*}$ & $<0.001^{*}$ & $<0.001^{*}$ \\
& CS3 & 10.57 & 13.38 & 10.16 & 11.14 \\
& CS4 & 11.58 & 13.19 & 12.92 & 13.82 \\
Male & $p$ value & $0.019^{*}$ & $0.002^{*}$ & $<0.001^{*}$ & $<0.001^{*}$ \\
& CS3 & 11.07 & 12.54 & 12.11 & 11.95 \\
& CS4 & 12.26 & 13.85 & 13.96 & 13.63 \\
& $p$ value & $0.031 *$ & $0.037^{*}$ & $0.069^{*}$ & $0.058^{*}$ \\
\hline
\end{tabular}

according to types of malocclusion in males and females. However, when all the data were compared, statistically significant differences were observed between groups I N and III $\mathrm{N}$ as well as III $\mathrm{N}$ and III $\mathrm{H}$. The arithmetic means for stage CS4 differed significantly for all participants and for females in all groups when malocclusions were compared with the group I N. In males, no statistically significant differences were noted for stage CS4.

The shortest lasting pubertal growth spurt was observed in group I N (1.07), followed by group III N (1.56) in which it lasted 6 months longer. Major differences between arithmetic means CS4-CS3 were seen in groups I H and III H (2.27 and 2.68, respectively). Both groups of high-angle patients ( $\mathrm{I} \mathrm{H}$ and III H) differed significantly from the normodivergent skeletal Class I (I N). In other comparative assessments, no statistically significant differences were observed (Table 4).

\section{Discussion}

Proper planning of orthodontic treatment is not possible without sound knowledge of craniofacial growth and development. The choice of a suitable method of treatment of the 
Table 3 The comparison of mean ages at CS3 and CS4 stages among groups with different types of malocclusion. ANOVA

\begin{tabular}{|c|c|c|c|c|c|c|c|c|c|c|c|c|}
\hline \multirow[t]{2}{*}{ Gender } & \multirow{2}{*}{$\begin{array}{l}\text { CVM } \\
\text { stage }\end{array}$} & \multicolumn{4}{|c|}{ Mean age } & \multirow[t]{2}{*}{$p$ value } & \multicolumn{6}{|c|}{ Post-hoc Tukey HSD } \\
\hline & & I N & III N & III $\mathrm{H}$ & I H & & I N vs. III N & I N vs. III H & I $\mathrm{N}$ vs. I H & III N vs. III H & III $\mathrm{N}$ vs. I H & III H vs. I H \\
\hline \multirow[t]{2}{*}{ Male + Female } & $\mathrm{CS} 3$ & 10.74 & 11.94 & 10.72 & 11.49 & $0.004 *$ & $0.014^{*}$ & 1 & 0.219 & $0.013 *$ & 0.689 & 0.204 \\
\hline & CS4 & 11.81 & 13.5 & 13.4 & 13.76 & $<0.001^{*}$ & $0.001 *$ & $0.003 *$ & $<0.001 *$ & 0.996 & 0.941 & 0.853 \\
\hline \multirow[t]{2}{*}{ Female } & $\mathrm{CS} 3$ & 10.57 & 11.38 & 10.16 & 11.14 & 0.061 & & & & & & \\
\hline & CS4 & 11.5 & 13.19 & 12.95 & 13.82 & $<0.001 *$ & $0.008^{*}$ & $0.025 *$ & $<0.001 *$ & 0.972 & 0.586 & 0.295 \\
\hline \multirow[t]{2}{*}{ Male } & $\mathrm{CS} 3$ & 11.07 & 12.54 & 12.11 & 11.95 & 0.057 & & & & & & \\
\hline & CS4 & 12.26 & 13.85 & 13.96 & 13.63 & 0.141 & & & & & & \\
\hline
\end{tabular}

growing patient and treatment duration are fundamental for successful therapeutic outcome [27, 28]. Growth mechanisms pose a challenge since they depend on many processes. The potential and pattern of the craniofacial growth is determined genetically and environmentally [29]. Genetic mechanisms that modulate facial growth have not been fully recognized, and accurate gene mapping is still the question of future studies $[30,31]$. Current studies on female twins indicate which structures rely more on genetic factors and which are more sensitive to environmental influences. Genes affect the shape of the nose, fullness of the lips, face size and pupillary distance, whereas environmental factors determine mandibular ramus height and horizontal facial asymmetry [32, 33]. The clinician, understanding the genetic and environmental background of the craniofacial growth and development, should also be aware of the proper duration of treatment of the young patient. Maxillary growth termination precedes the mandibular one; hence, all the therapeutic activities within the midface should be performed without delay [34, 35]. Mandibular growth, on the other hand, is related to facial muscle function and total rotation, which comprises the matrix and the intramatrix rotation. Additionally, one has to allow for

Table 4 The comparison of mean duration (in years) of pubertal growth spurt for different types of malocclusion. A linear model with interaction variables. CS4-CS3 - the difference between the means of the compensation mechanisms [36]. Another critical factor is the variability of the rate of mandibular growth, with its accelerations and slowdowns [37]. From the perspective of dentofacial orthopaedics, the period of pubertal growth spurt, usually lasting several months, merits utmost attention due to the highest acceleration of mandibular growth in that period $[27,38]$.

There are a number of papers concerning the growth spurt period in patients with disturbed horizontal growth component. The majority of researchers confirm a longer period of pubertal growth spurt in patients with skeletal Class III [22, 23, 39]. The difference between patients with skeletal Class I and Class III is a matter of 4.8 to 5.9 months, which concurs with the results of the present study (6 months). The only discrepancy here is the absence of statistically significant differences between group III $\mathrm{N}$ and the others. The authors of previously published papers did reveal such differences. This discrepancy may be due to a different number of subjects in study groups, to standard deviation which has a higher value here (probably resulting from higher intersubject variability), and most of all a different method of statistical analysis. The linear model with interaction variables that has been adopted

chronological age related to CS4 and CS3 (the duration of the pubertal growth spurt), $\mathrm{F}$ - result of ANOVA, df - degrees of freedom

\begin{tabular}{|c|c|c|c|c|}
\hline Type of malocclusion & CS4-CS3 [year] & $\mathrm{F}$ & $\mathrm{df}$ & $p$ value \\
\hline $\begin{array}{c}\text { I N } \\
\text { III N }\end{array}$ & $\begin{array}{l}1.07 \\
1.56\end{array}$ & 0.947 & 1,104 & $0.333^{*}$ \\
\hline $\begin{array}{l}\text { I N } \\
\text { III H }\end{array}$ & $\begin{array}{l}1.07 \\
2.68\end{array}$ & 8.03 & 1,107 & $0.006^{*}$ \\
\hline $\begin{array}{l}\text { I N } \\
\text { I H }\end{array}$ & $\begin{array}{l}1.07 \\
2.27\end{array}$ & 4.61 & 1,106 & $0.034 *$ \\
\hline $\begin{array}{l}\text { III N } \\
\text { III H }\end{array}$ & $\begin{array}{l}1.56 \\
2.68\end{array}$ & 3.05 & 1,99 & 0.084 \\
\hline $\begin{array}{c}\text { III N } \\
\text { I H }\end{array}$ & $\begin{array}{l}1.56 \\
2.27\end{array}$ & 1.25 & 1,98 & 0.265 \\
\hline $\begin{array}{c}\text { III H } \\
\text { I H }\end{array}$ & $\begin{array}{l}2.68 \\
2.27\end{array}$ & 0.365 & 1,101 & 0.547 \\
\hline
\end{tabular}


here seems the most suitable one regarding the cross-sectional character of the study and no uniformity of patients in stages CS3 and CS4.

Studies concerning the duration of pubertal growth spurt in high-angle patients are still scarce $[25,40]$. There is one paper that compares skeletal Class I and II also in patients with skeletal open bite [41]. The number of high-angle patients is less numerous (83 subjects) in comparison with the present study (105). The results are similar to those presented herethey also confirm longer pubertal growth spurt in patients with skeletal open bite. The duration of pubertal growth spurt in normodivergent patients in the studies by Ghaleb et al. [41] is 1.109 , which is almost identical with the results presented above (1.07). However, the difference between stage CS4 and CS3 for high-angle patients is smaller by 0.78 (approximately 10 months, if the I $\mathrm{H}$ group is taken into account). In both studies, the differences are statistically significant, and the discrepancy in the duration of growth spurt in patients with skeletal open bite may be related to a different climate zone. Turkey is subtropical with temperatures higher than those in Poland with its moderate climate. Puberty is affected by both environmental and genetic factors [42]. The Americans, for example, are shorter than the Dutch [1]. Some races or ethnic groups mature faster than others [43].

A study by Çelebi et al. [25] is another one that deals with pubertal growth spurt. The authors failed to find statistically significant differences between groups with different vertical and horizontal cephalometric parameters. However, they used the hand-wrist method acc. to Greulich and Pyle and not the CVM method, and the number of high-angle patients was lower (35 subjects). The fact that it was a longitudinal study works in its favour. The authors claim that cross-sectional studies cannot possibly reflect the actual changes in the human body, an observation that cannot be disputed. On the other hand, the purpose of the hand and wrist radiograph is only to determine the skeletal age. Therefore, prescribing it routinely for a young patient is contrary to radiological protection. A cephalometric radiograph will find its application in the diagnostics of malocclusions, treatment planning, monitoring its course, observation of growth and assessment of bone age [44]. It visualizes not only both jaws but also paranasal sinuses, the hard palate, tonsils and airways' patency [45, 46]. Assessment of the cranial shape may be useful in diagnosing patients with genetic disorders [47]. Many ENT specialists, speech therapists, paediatricians and geneticists will find a cephalometric radiograph helpful. Being equipped with this multifunctional imaging tool, ordering an additional radiograph, merely to confirm the skeletal age, seems pointless. Many reports in literature confirm the repeatability of the CVM method [12, 13].

Differences in the duration of the pubertal growth spurt in different types of malocclusion are clinically significant. In open bites, an orthodontist will have more time at their disposal to undertake orthopaedic therapy consisting, for example, of intruding molars by means of occlusal pads or miniimplants. If this therapy is effective, it will prevent the patient from undergoing orthognathic surgery. It is our observation that in skeletal Class III, the increased growth potential will adversely intensify the skeletal defect. Awareness of the duration of the pubertal growth spurt will be useful when surgical procedures are planned. With the growth completed, the patient may hope for a more stable effect [48]. It has to be remembered that a teenager with a high-angle defect may grow longer than their normodivergent peer. In the present study, the oldest patients with skeletal open bite were almost 17.5 years old. These observations correlate with those by Behrents [26].

In females, and in the group comprising both sexes, the age for the CS4 stage statistically significantly differed in the following comparisons: I N vs. III N, I N vs. I H and I N vs. III H. A similar tendency was not observed in males, which may be due to fewer male participants in the study. Patients still tend to perceive malocclusions as an aesthetic defect; hence, girls' parents are more interested in treatment of their offspring. The onset of growth spurt in males in comparison with females came half a year ( $\mathrm{IN}$ ) to 2 years later (III H), which is consistent with reports in literature [49].

The domination of females over males may have also affected the occurrence of the growth spurt earlier and minutely extend the duration of the growth spurt in both genders. The differences between the mean chronological age regarding CS4 and CS3 in males was lower than in females but the tendency in the duration of the growth spurt: normodivergent skeletal Class I < normodivergent skeletal Class III < highangle skeletal Class I < high-angle skeletal Class III is recurring in females, males and in both genders.

Even though there were no publications involving bigger samples of high-angle patients when the present paper was being prepared, there is a clear need to examine larger populations from various clinical centres, or to perform metaanalysis covering a period of several years once new papers on this topic are published. In cross-sectional studies, the size of the sample is fundamental.

Several problems were encountered when the necessary material was being pooled. There were fewer number of cephalometric radiographs of patients with normal anteroposterior and vertical measurements than it had been expected (patients with skeletal Class I are infrequent attendees at the orthodontic clinics and they seldom have indications for having a cephalometric radiograph taken). Furthermore, patients with skeletal Class III were frequently excluded from studies since they had already commenced their orthodontic treatment, which is consistent with studies by Ghaleb et al. [41]. Moreover, high-angle patients were usually close to angle $38^{\circ}$, which means they were borderline and could not be included in the study due to NS/ML > $39^{\circ}$ criterion. 


\section{Conclusions}

Based on the above results, pubertal growth spurt in highangle patients persists statistically significantly longer than in normodivergent patients. The following tendency was observed in the duration of the pubertal growth spurt: normodivergent skeletal Class $\mathrm{I}<$ normodivergent skeletal Class III $<$ high-angle skeletal Class I $<$ high-angle skeletal Class III. This tendency has statistical significance only in high-angle patients in comparison with normodivergent skeletal Class I. The research also confirmed that pubertal growth spurt in males has its onset half a year to 2 years later than in females, depending on the defect.

Supplementary Information The online version contains supplementary material available at https://doi.org/10.1007/s00784-021-03799-7.

Author contribution All authors contributed to the study conception and design. Material preparation, data collection and analysis were performed by Agnieszka Szemraj-Folmer. The first draft of the manuscript was written by Agnieszka Szemraj-Folmer and all authors commented on previous versions of the manuscript. All authors read and approved the final manuscript

Funding This research did not receive any specific grant from funding agencies in the public,

\section{Compliance with ethical standards}

Ethical approval and consent to participate Ethical approval was obtained from The Independent Bioethics Committee at The Medical University in Gdańsk prior to data collection (NKBBN/43/2017). All procedures performed in studies involving human participants were in accordance with the ethical standards of the institutional research committee and with the 1964 Helsinki declaration and its later amendments or comparable ethical standards. For this type of study (a retrospective, cross-sectional study), formal consent is not required.

Conflict of interest The authors declare no conflict of interest.

Open Access This article is licensed under a Creative Commons Attribution 4.0 International License, which permits use, sharing, adaptation, distribution and reproduction in any medium or format, as long as you give appropriate credit to the original author(s) and the source, provide a link to the Creative Commons licence, and indicate if changes were made. The images or other third party material in this article are included in the article's Creative Commons licence, unless indicated otherwise in a credit line to the material. If material is not included in the article's Creative Commons licence and your intended use is not permitted by statutory regulation or exceeds the permitted use, you will need to obtain permission directly from the copyright holder. To view a copy of this licence, visit http://creativecommons.org/licenses/by/4.0/.

\section{References}

1. Proffit WR, Fields H, Larson B, Sarver D (2013) Contemporary orthodontics, 5th. Mosby, St Louis
2. Suda N, Ishii-Suzuki M, Hirose K, Hiyama S, Suzuki S, Kuroda T (2000) Effective treatment plan for maxillary protraction: is the bone age useful to determine the treatment plan? Am J Orthod Dentofac 118:55-62

3. Wong RW, Alkhal HA, Rabie AB (2009) Use of cervical vertebral maturation to determine skeletal age. Am J Orthod Dentofac 136: 484.e1-484.e6

4. Bian Z, Guo Y, Lyu X, Yang Z, Cheung JPY (2020) Relationship between hand and wrist bone age assessment methods. Medicine (Baltimore) 99:e22392

5. Jeong SW, Cho JH, Jung HW, Shim KS (2018) Near final height in Korean children referred for evaluation of short stature: clinical utility and analytical validity of height prediction methods. Ann Pediatr Endocrinol Metab 23:28-32

6. Lamparski DG (1972) Skeletal age assessment utilizing cervical vertebrae [master's thesis]. Pittsburgh, Penn; Department of Orthodontics, the University of Pittsburgh

7. Hassel B, Farman A (1995) Skeletal maturation evaluation using cervical vertebrae. Am J Orthod Dentofac Orthop 107:58-66

8. Baccetti T, Franchi L, McNamara JA Jr (2005) The cervical vertebral maturation (CVM) method for the assessment of optimal treatment timing in dentofacial orthopedics. Semin Orthod 11:119-129

9. Nestman T, Marshall S, Qian F et al (2011) Cervical vertebrae maturation method morphologic criteria: poor reproducibility. Am J Orthod Dentofac 140:182-188

10. Morris KM, Fields HW Jr, Beck FM, Kim DG (2019) Diagnostic testing of cervical vertebral maturation staging: an independent assessment. Am J Orthod Dentofac Orthop 156:626-632

11. Perinetti G, Caprioglio A, Contardo L (2014) Visual assessment of the cervical vertebral maturation stages: a study of diagnostic accuracy and repeatability. Angle Orthod 84:951-995

12. Al Khal HA, Wong RW, Rabie AB (2008) Elimination of handwrist radiographs for maturity assessment in children needing orthodontic therapy. Skelet Radiol 37:195-200

13. Lai EHH, Liu JP, Chang JZC, Tsai SJ, Yao CCJ, Chen MH, Lin CP (2008) Radiographic assessment of skeletal maturation stages for orthodontic patients: hand-wrist bones or cervical vertebrae? J Formos Med Assoc 107:316-325

14. Chen LL, Xu TM, Jiang HJ et al (2008) Quantitative cervical vertebral maturation assessment in adolescents with normal occlusion: a mixed longitudinal study. Am J Orthod Dentofac 134:720.e1720.e7

15. Alkhal HA, Wong RW, Rabie AB (2008) Correlation between chronological age, cervical vertebral maturation and Fishman's skeletal maturity indicators in southern Chinese. Angle Orthod 78:591-596

16. Fishman LS (1979) Chronological versus skeletal age, an evaluation of craniofacial growth. Angle Orthod 49:181-189

17. Safavi SM, Beikaii H, Hassanizadeh R, Younessian F, Baghban AA (2015) Correlation between cervical vertebral maturation and chronological age in a group of Iranian females. Dent Res J (Isfahan) 12:443-448

18. Melsen B, Melsen F (1982) The postnatal development of the palatomaxillary region studied on human autopsy material. Am J Orthod Dentofac 82:329-342

19. Marshall WA, Tanner JM (1986) Puberty. In: Falkner F, Tannner JM (ed) Human growth, vol 2, 2nd. Plenum Publishing, New York, pp. $171-203$

20. Anderson DL, Thompson G, Popovich F (1975) Interrelation of dental maturity, skeletal maturity, height and weight from age 4 to 14 years. Growth 39:453-462

21. Haiter-Neto F, Kurita LM, Menezes AV, Casanova MS (2006) Skeletal age assessment: a comparison of 3 methods. Am J Orthod Dentofac 130:435.e15-435.e20 
22. Jeelani W, Fida M, Shaikh A (2016) The duration of pubertal growth peak among three skeletal classes. Dental Press J Orthod 21:67-74

23. Kuc-Michalska M, Baccetti T (2010) Duration of the pubertal peak in skeletal Class I and Class III subjects. Angle Orthod 80:54-57

24. Salazar-Lazo R, Arriola-Guillén LE, Flores-Mir C (2014) Duration of the peak of adolescent growth spurt in Class I and II malocclusion subjects using a cervical vertebrae maturation analysis. Acta Odontol Latinoam 27:96-101

25. Çelebi F, Celikdelen M, Biçakçi AA (2017) Peak timing of the pubertal growth spurt according to the sagittal and vertical skeletal patterns. Sch J Dent Sci 4:129-133

26. Behrents RG (1984) A treatise on the continuum of growth in the ageing craniofacial skeleton. Ann Arbor, Mich; Center for Human Growth and Development, University of Michigan

27. Baccetti T, Franchi L, Toth LR, McNamara JA Jr (2000) Treatment timing for twin block therapy. Am J Orthod Dentofac 118:159-170

28. Reyes BC, Baccetti T, Mc Namara JA Jr (2006) An estimate of craniofacial growth in Class III malocclusion. Angle Orthod 76: 577-584

29. Weinberg SM, Cornell R, Leslie EJ (2018) Craniofacial genetics: where have we been and where are we going? PLoS Genet 14: e1007438

30. Manlove AE, Romeo G, Venugopalan SR (2020) Craniofacial growth: current theories and influence on management. Oral Maxillofac Surg Clin North Am 32:167-175

31. Sun Z, da Fontoura CSG, Moreno M, Holton NE, Sweat M, Sweat Y, Lee MK, Arbon J, Bidlack FB, Thedens DR, Nopoulos P, Cao $\mathrm{H}$, Eliason S, Weinberg SM, Martin JF, Moreno-Uribe L, Amendt BA (2018) FoxO6 regulates hippo signaling and growth of the craniofacial complex. PLoS Genet 14:e1007675

32. Djordjevic J, Zhurov AI, Richmond S, Visigen Consortium (2016) Genetic ana environmental contributions to facial morphological variation: a 3D population-based twin study. PLoS One 11: $\mathrm{e} 0162250$

33. Roosenboom J, Hens G, Mattern BC et al (2016) Exploring the underlying genetics of craniofacial morphology through various sources of knowledge. Biomed Res Int:3054578

34. Baccetti T, McGill JS, Franchi L et al (1998) Skeletal effects of early treatment of Class III malocclusion with maxillary expansion and face-mask therapy. Am J Orthod Dentofac 113:333-343

35. Franchi L, Baccetti T, McNamara JA Jr (1998) Shape-coordinate analysis induced by rapid maxillary expansion and facial mask therapy. Am J Orthod Dentofac 114:418-426

36. Björk A, Skieller V (1983) Normal and abnormal growth of the mandible. A synthesis of longitudinal cephalometric implant studies over a period of 25 years. Eur J Orthod 5:1-46
37. Woodside DG (1974) In: Salzman JA (ed) Orthodontics in daily practice. Philadelphia, JB Lippincott

38. Faltin K, Faltin RM, Baccetti T, Franchi L, Ghiozzi B, McNamara JA Jr (2003) Long-term effectiveness and treatment timing for Bionator therapy. Angle Orthod 73:221-230

39. García-Drago AG, Arriola-Guillén LE (2014) Duration of the peak of growth in Class I and III subjects using the Baccetti's cervical vertebrae maturation analysis on lateral cephalometric radiographs. Oral Health Dent Manag 13:963-966

40. Perinetti G, Rosso L, Riatti R, Contardo L (2016) Sagittal and vertical craniofacial growth pattern and timing of circumpubertal skeletal maturation: a multiple regression study. Biomed Res Int

41. Ghaleb H, Akl R, Khoury ES, Ghoubril J (2019) Estimation and comparison of the duration of the pubertal peak in skeletal Class II and Class I subjects using the cervical vertebrae maturation index method. J Contemp Dent Pract 20:1095-1101

42. Omariba G, Xiao J (2020) Association study of puberty-related candidate genes in Chinese female population. Int J Genomics 2020:1426761

43. Zhang A, Sayre JW, Vachon L, Liu BJ, Huang HK (2009) Racial differences in growth patterns of children assessed on the basis of bone age. Radiology 250:228-235

44. Segner D, Hasund A (1994) Individualisierte Kephalometrie. Segner, Hamburg

45. Ansar J, Singh R, Bhattacharya P, Agarwal D, Verma S, Maheshwari S (2015) Cephalometric evaluation of the airway dimensions in subjects with different growth patterns. J Orthod Res 3:108

46. Guttal KS, Burde KN (2013) Cephalometric evaluation of upper airway in healthy adult population: a preliminary study. J Oral Maxillofac Radiol 1:55-60

47. Solomon BD, Muenke M (2012) When to suspect a genetic syndrome. Am Fam Physician 86:826-833

48. Jamilian A, Darnahal A, Perillo L (2015) Orthodontic preparation for orthognathic surgery. In: Motamedi MH (ed) a textbook of advanced oral and maxillofacial surgery. Volume 2, 1st edn. IntertechOpen, pp 105-118

49. Hosni S, Burnside G, Watkinson S, Harrison JE (2018) Comparison of statural height growth velocity at different cervical vertebral maturation stages. Am J Orthod Dentofac Orthop 154: $545-553$

Publisher's note Springer Nature remains neutral with regard to jurisdictional claims in published maps and institutional affiliations. 